\title{
O DESCOMPASSO
}

ENTRE A ESTRUTURA ACADÊMICA E A ESTRUTURA

\section{MUSEAL EM MUSEUS} UNIVERSITÁRIOS: O CASO DO MUSEU NACIONAL (UFRJ)

SILVIA REIS, UNIVERSIDADE FEDERAL DO RIO DE JANEIRO, RIO DE JANEIRO, RIO DE JANEIRO, BRASIL

Cientista Social (Bacharelado e Licenciatura) pela Universidade Federal Fluminense, Especialista em Paleopatologia pela ENSP/FIOCRUZ, mestre em História Comparada e doutora em Arqueologia pela Universidade Federal do Rio de Janeiro (UFRJ). Arqueóloga (Bioarqueologia Humana) do Departamento de Antropologia do Museu Nacional/UFRJ. E-mail: sreis@mn.ufrj.br

ORCID: https://orcid.org/0000-0003-2965-7834

LUCIANA WITOVISK, UNIVERSIDADE FEDERAL DO RIO DE JANEIRO, RIO DE JANEIRO, RIO DE JANEIRO, BRASIL

Bióloga pela Universidade Federal do Paraná, mestre em Ciências (Botânica) pela Universidade de São Paulo e doutora em Geociências (Paleontologia) pela Universidade Federal do Rio de Janeiro (UFRJ). Docente em Paleobotânica, Departamento de Geologia e Paleontologia do Museu Nacional/UFRJ.

E-mail: luwitovisk@mn.ufrj.br

MARIANE TARGINO, UNIVERSIDADE FEDERAL DO RIO DE JANEIRO, RIO DE JANEIRO, RIO DE JANEIRO, BRASIL

Bióloga pela Universidade Federal do Rio de Janeiro, mestre em Zoologia pelo Museu Nacional/Universidade Federal do Rio de Janeiro (UFRJ), doutora em Zoologia pela Universidade de São Paulo. Gerente da Coleção Ictiológica, Departamento de Vertebrados do Museu Nacional/UFRJ.

E-mail: marianetargino@mn.ufr.br ORCID: https://orcid.org/0000-0001-7155-9969

(continua...) 


\section{O DESCOMPASSO ENTRE A ESTRUTURA ACADÊMICA E A ESTRUTURA MUSEAL EM MUSEUS UNIVERSITÁRIOS: O CASO DO MUSEU NACIONAL (UFRJ)}

(continuação)

MARCELO BRITTO, UNIVERSIDADE FEDERAL DO RIO DE JANEIRO, RIO DE JANEIRO, RIO DE JANEIRO, BRASIL

Biólogo e mestre em Ciências Biológicas (Zoologia) pela Universidade Federal do Rio de Janeiro (UFRJ), doutor em Zoologia pela Universidade de São Paulo. Docente em Ictiologia, Departamento de Vertebrados do Museu Nacional/UFRJ.

E-mail: mrbritto@mn.ufrj.br

ORCID https://orcid.org/0000-0002-0611-6923

FERNANDA PIRES SANTOS, UNIVERSIDADE FEDERAL DO RIO DE JANEIRO, RIO DE JANEIRO, RIO DE JANEIRO, BRASIL

Historiadora (Bacharelado e Licenciatura), Especialização em Preservação e Gestão do Patrimônio Cultural pela FIOCRUZ, Mestrado em Museologia e Patrimônio pela UNIRIO. Museóloga da Seção de Museologia do Museu Nacional/UFRJ.

E-mail: fernandapires@mn.ufrj.br

DOI

DOI: http://dx.doi.org/10.11606/issn.1980-4466.v15i30p62-90 


\section{O DESCOMPASSO ENTRE A ESTRUTURA ACADÊMICA E A ESTRUTURA MUSEAL EM MUSEUS UNIVERSITÁRIOS: O CASO DO MUSEU NACIONAL (UFRJ)}

SILVIA REIS, LUCIANA WITOVISK, MARIANE TARGINO, MARCELO BRITTO, FERNANDA PIRES SANTOS

\section{RESUMO}

O Museu Nacional foi criado em 1818, por D. João VI. Em 200 anos passou pela estruturação de suas coleções, pela incorporação à Universidade do Brasil, em 1946, atual Universidade Federal do Rio de Janeiro, e tornou-se referência nacional e internacional nas áreas da História Natural e Antropologia por meio de suas coleções e excelência em ensino, pesquisa e extensão. O incêndio ocorrido em 2 de setembro de 2018 marcou mais um importante capítulo da sua história - a luta pela reconstrução. Parte desse esforço foi a composição de uma comissão de servidores que se debruçou sobre a revisão e construção de um novo regimento para a instituição. Assim, este trabalho traz à luz análises sobre a complexidade da estrutura do Museu Nacional e debate alguns problemas práticos que dificultam a sua plena realização como museu e parte integrante de uma estrutura universitária. Tal debate é extensível e imprescindível para os museus universitários, onde a estrutura museal pode ser passível de limitações por uma estrutura universitária voltada para unidades acadêmicas padrão ou órgãos suplementares não autônomos, e que não contempla as particularidades do funcionamento de um museu. Por fim, é proposta a criação de uma estrutura museal-acadêmica, onde todas as categorias de servidores públicos poderiam atuar de forma colaborativa, em prol de uma instituição diversa, dinâmica, plural, em diálogo aberto com a universidade e a sociedade, pronta para enfrentar os novos paradigmas do século XXI.

\section{PALAVRAS-CHAVE}

Museus universitários, Administração de museus, Gestão democrática da educação, Equipes. 


\section{THE MISMATCH BETWEEN AN ACADEMIC STRUCTURE AND A MUSEUM STRUCTURE IN UNIVERSITY MUSEUMS: THE CASE OF THE MUSEU NACIONAL (UFRJ)}

SILVIA REIS, LUCIANA WITOVISK, MARIANE TARGINO, MARCELO BRITTO, FERNANDA PIRES SANTOS

\section{ABSTRACT}

The National Museum/UFRJ was created in 1818 by D. João VI. In its two hundred years of history, it went through the process of structuring its collections and being incorporated into the University of Brazil in 1946, currently the Federal University of Rio de Janeiro (UFRJ), becoming a national and international reference for areas of Natural History and Anthropology, through its collections and excellence in teaching, research and extension. The fire on September 2, 2018 marked another important chapter in its history - the struggle for its reconstruction. Part of this effort was the composition of a committee of servants that looked at the revision and the construction of a new statute for the institution. Thus, this paper analyzes the complexity of the structure of National Museum and discussing some practical problems that hinder its filled role as a museum and as an integrating part of a university. This debate is extensible and necessary to all museums immersed in a university framework, where the museum structure may be limited by a university structure that encompasses only standard academic units or supplementary organs with no autonomy, not contemplating the particularities of typical museums. Lastly, the creation of a museum-academic structure is proposed where all categories of civil servants could act collaboratively in favor of a diverse, dynamic, plural institution, openly dialoguing with the university and society, ready to face the new paradigms of the 21st century.

\section{KEYWORDS}

University museums, Museum administration, Democratic management of education, Staff. 


\section{O MUSEU NACIONAL ENQUANTO MUSEU UNIVERSITÁRIO}

Em geral, um museu universitário é entendido como um museu sob responsabilidade total ou parcial de uma universidade, com salvaguarda do acervo, recursos humanos e espaço físico (ALMEIDA, 2001). Segundo Mendonça (2017, p. 38), os museus universitários

\footnotetext{
estão sob tutela de uma universidade; possuem estruturas mínimas de pessoal e espaço físico para dar suporte às cinco principais funções museológicas (aquisição, conservação, pesquisa, comunicação e educação); e que servem e/ou serviriam no todo, ou em parte de sua existência, à tríade universitária composta pela pesquisa (produção de conhecimento), ensino (educação superior) e extensão (difusão cultural e relação com a comunidade externa).
}

De acordo com Lourenço (2019), não pode existir uma definição de museu universitário distinta de suas instituições congêneres, uma vez que todo museu é um museu e, para tal, segue a mesma definição debatida pelo Conselho Internacional de Museus (Icom) assim como os mesmos códigos de ética e princípios (INTERNATIONAL COUNCIL OF MUSEUMS, 2018; 2017). Dada a heterogeneidade e os desafios enfrentados pelos museus em universidades até hoje, Lourenço (2019) exorta que é papel do International Committee for University Museums and Collections (UMAC), instância do Icom, responder "com responsabilidade e clareza", tendo como fundamento 
todo o arcabouço de princípios e orientações sobre o que é um museu e sua função social

We need to be able to clearly say to rectors, university administrators and managers, professors, researchers, librarians, students, that natural history specimens in a dozen showcases in a corridor are not a museum.

We need to tell them that museums, collections and heritage are not their property.

We need to be able to say that heritage is not to be moved or disposed of according to the fluctuations of teaching and research, or personal taste.

We need to be able to say that heritage requires highly specialised professionals for its preservation and care. And we need to be able to say that museums, collections and heritage have to be accessible to everybody, not just a few selected friends, colleagues and students. ${ }^{1}$ (LOURENÇO, 2019, p.4).

Nesse sentido, o Museu Nacional, com mais de 200 anos de trajetória, mostra-se um caso especial de museu que passou a integrar a estrutura universitária.

O Museu Nacional foi criado em 6 de junho de 1818, como Museu Real, por meio de decreto assinado por D. João VI, com o intuito de "propagar os conhecimentos e estudos das sciencias naturaes no Reino do Brazil" (BRASIL, 1889). Formado inicialmente por materiais coligidos em diferentes lugares, antes guardados de forma dispersa (segundo o decreto supracitado), o Museu se localizava em edifício no Campo de Santana, no Rio de Janeiro, desapropriado de João Rodrigues Pereira Almeida, o qual teria concordado em vendê-lo. Dentre as coleções já existentes, possivelmente absorvidas pelo Museu Nacional, é citada a famosa Casa dos Pássaros, primeiro Gabinete de História Natural do Brasil e das Américas, criada em 1784 pelo vice-rei Luis de Vasconcelos e Sousa e se tratava de uma coleção de aves abatidas e taxidermizadas, expostas ou remetidas para Portugal, tendo sido extinta em 1813 (ABSOLON et al., 2018).

1 Tradução livre: Nós precisamos ser capazes de dizer claramente a reitores, administradores e gestores de universidade, professores, pesquisadores, bibliotecários, alunos, que espécimes de história natural em uma dúzia de vitrines em um corredor não são um museu. Nós precisamos contar para eles que museus, coleções e patrimônio não são suas propriedades. Nós precisamos ser capazes de dizer que patrimônio necessita de profissionais altamente especializados para sua preservação e cuidado. E nós precisamos ser capazes de dizer que museus, coleções e patrimônio devem ser abertos para todos, não apenas alguns amigos seletos, colegas e alunos. 
A construção do Museu Nacional, ao longo do século XIX, como primeiro museu de história natural brasileiro, acompanha a trajetória do desenvolvimento das ciências no Brasil. Se, a princípio, fora criado para fomentar pesquisas sobre materiais e riquezas do território que poderiam ser economicamente úteis (FERNANDES et al., 2014), o Museu diversificou sua atuação para além desta perspectiva utilitarista, buscando respostas para as questões que movimentavam a Ciência em âmbito internacional. A mudança, em 1892, para o Paço de São Cristóvão, antiga residência da família real, ampliou o espaço expositivo e de pesquisa, além de somar um novo nível simbólico ao museu.

No século XX, o Museu Nacional passou por diversas mudanças, atuando e refletindo de certa maneira a conjuntura histórica de cada momento. Nesse sentido, podemos citar a atuação importante de Luiz de Castro Faria para a promoção do reconhecimento e proteção do patrimônio arqueológico no Brasil, inclusive com elaboração de legislação específica (SIMÃO, 2009). Também foi sob a direção de Heloísa Alberto Torres (1938-1955) que se empreendeu uma grande restauração e revitalização da sede. Para a reestruturação das exposições, as portas foram fechadas aos visitantes em 1941, e a reinauguração foi possível apenas em 1947, após árduos conflitos (RIBEIRO, 2019). Somente na década de 1990 um novo movimento de restauração da sede e revitalização das exposições teve início, se estendendo às duas primeiras décadas do século XXI, novamente em meio às idas e vindas políticas e restrições orçamentárias à ciência e à cultura (DUARTE, 2019).

Essas e outras ações pavimentaram o caminho para a implementação de grupos de pesquisa fortes e coleções bem estruturadas e, subsequentemente, a instalação de cursos de pós-graduação. Em plena ditadura militar, o Museu Nacional criou, em 1968, sua primeira pós-graduação, em Antropologia Social. Em 1972, surgiram os programas de pós-graduação em Zoologia e Botânica. Esses cursos representam a entrada do Museu Nacional no circuito acadêmico formal de educação. Os demais programas de pós-graduação do Museu, criados a partir da virada para o século XXI (Arqueologia, Patrimônio Geopaleontológico, Linguística e Línguas Indígenas), aliados aos programas lato sensu (Geologia do Quaternário, Gramática Gerativa e Estudos de Cognição, Línguas Indígenas Brasileiras), mais que triplicaram a capacidade de formação de pessoal especializado, 
bem como ampliaram o capital científico da instituição, especialmente através do incremento de seus quadros de pessoal credenciado e discente. Nesse sentido, as bases e colaborações desenvolvidas ao longo dos últimos anos foram relevantes para esse novo momento da instituição.

Quando de sua criação, em 1818, o Museu era composto por diretor, porteiro, um ajudante de preparações zoológicas, escriturário e um escrivão de receita e despesas (LACERDA, 1905). Ao longo do século XIX e início do século XX, essa estrutura foi se modificando e se tornando maior e mais complexa, chegando a ser composta por profissionais como naturalistas, taxidermistas, preparadores e naturalistas-viajantes.

Em 1946, houve a incorporação do Museu Nacional à Universidade Federal do Rio de Janeiro, na época chamada de Universidade do Brasil. Porém, sua adequação à estrutura universitária se deu apenas após a reforma de 1968 (BRASIL, 1968) e com o regimento interno de 1971. Antecedeu este episódio a criação do Ministério da Educação e Saúde Pública, em 1930, quando o Museu Nacional passou a integrar o recém-criado ministério como órgão do Departamento Nacional do Ensino, assim como a Universidade do Rio de Janeiro, as Escolas Superiores Federais em outros estados, o Colégio Pedro II, a Escola de Belas Artes, o Instituto Benjamin Constant, o Museu Histórico Nacional, entre outros, no Decreto № 19.444 (BRASIL, 1930).

Atualmente, os servidores de universidade públicas se dividem em apenas dois planos de carreira, docentes e técnicos administrativos em educação (BRASIL, 2005a; 2012). A categoria docente é padronizada, com servidores que, em geral, possuem titulação de doutorado e atribuições como o oferecimento de aulas em cursos de graduação e/ou pós-graduação, a orientação de alunos e estagiários, e atuação em pesquisa e extensão; a categoria de técnicos-administrativos é extremamente diversa e inclui servidores com diferentes níveis de titulação e com diversos tipos de atuação (arquiteto, engenheiro, médico, biólogo, museólogo, programador visual, técnico de laboratório, motorista, assistente de som, auxiliar de laboratório etc.) (BRASIL, 2005b). O tripé em que se sustentam as universidades públicas brasileiras, formado por ensino, pesquisa e extensão, pode ser aplicado a todo o quadro funcional, sem distinção de cargos, embora cada cargo tenha atribuições próprias. 
Atualmente, o estatuto da Universidade Federal do Rio de Janeiro (UFRJ) divide a infraestrutura universitária em unidades acadêmicas, que são órgãos de execução do ensino, da pesquisa e da extensão, e órgãos suplementares de natureza técnica, científica e cultural. Os museus da UFRJ estão em uma dessas duas categorias, não existindo uma categoria própria que contemple as particularidades de um museu e sua estrutura (UNIVERSIDADE FEDERAL DO RIO DE JANEIRO, 2019a).

O que se observa na prática é que museus não se encaixam inteiramente como unidades acadêmicas, porque estas em geral giram em torno de cursos de graduação que contém alunos na casa dos milhares. A estrutura de laboratórios de pesquisa, bibliotecas e de acervos científicos existe em unidades acadêmicas, porém não costuma ser mais expressiva do que as demais estruturas necessárias para o funcionamento de um curso de graduação de grande porte.

No caso dos museus, a atenção é voltada principalmente para os acervos que o compõem e todas as atividades que giram em torno deles, $\mathrm{o}$ que envolve múltiplos profissionais.

Os museus universitários designados como órgãos suplementares também têm apresentado problemas comuns, tais como falta de autonomia e pessoal lotado no próprio órgão, como nos museus da Universidade Federal da Bahia (SMANIA-MARQUES; SILVA, 2011), problemas no repasse de verbas, no entendimento de sua função acadêmica e museal, em última instância havendo sufocamento das instituições, como os casos do Museu Câmara Cascudo, da Universidade Federal do Rio Grande do Norte (PESSOA, 2008), e dos museus das Universidades de Pernambuco (RIBEIRO, 2013).

Smania-Marques e Silva (2011, p. 63) já haviam exposto a argumentação de que "os museus universitários possuem muitas missões e atribuições particulares, frutos das atividades museais e, portanto, não podem ser tratados de forma igualitária a outros órgãos institucionais" e que "o modus operandi das universidades interfere fortemente no modus operandi dos museus que estão sob a sua salvaguarda e isso traz diversas consequências e complicações." (SMANIA-MARQUES; SILVA, 2011, p. 77).

Em 2 de setembro de 2018, o Museu Nacional sofreu com um incêndio de proporções catastróficas. Se a instituição já enfrentava diversas 
dificuldades, como o progressivo corte de verba e apoio, o incêndio veio escancarar o abandono e o desprestígio da ciência e da cultura no Brasil. No entanto, em meio à profunda tristeza e dor, a comunidade do Museu Nacional está viva e se recusa a aceitar os votos (e desejos) de luto. A reconstrução se tornou motor de resistência e resiliência.

Destarte, um dos elementos que se mostrou urgente revisitar foi a revisão e elaboração de um novo regimento interno para o Museu Nacional, posto que o vigente data de 1971 e não corresponde adequadamente à realidade da instituição. Tal questão está em debate há muitos anos, principalmente sobre o método a ser aplicado. Todavia, para a reconstrução do Museu tornou-se premente a aceleração desse processo.

Assim, neste artigo, nos debruçamos sobre um dos elementos desafiadores na revisão do regimento de um museu universitário, com a história e trajetória do Museu Nacional: a relação entre a estrutura museal e a estrutura acadêmica. Além disso, trabalhamos com exemplos práticos (alocação e representatividade de servidores, curadoria de coleções, pós-graduação, código para disciplinas de graduação e possibilidade para abertura de cursos lato sensu, composta por pessoal qualificado da instituição) dos problemas causados quando uma instituição complexa é acomodada em uma estrutura mínima. Analisamos também em que medida é possível que o Museu Nacional se realize como museu e como unidade acadêmica em uma universidade. É preciso garantir que estas estruturas sejam indissociáveis.

\section{REGIMENTO DO MUSEU NACIONAL}

A revisão e construção de um novo regimento para o Museu Nacional constitui um grande desafio, pois não se trata apenas de uma adequação às leis e normas vigentes. Trata-se de um novo olhar sobre uma instituição bicentenária, que se mostra dinâmica, plural e prestes a se adaptar aos novos paradigmas do século XXI, que se impõe a todos os museus e instituições de pesquisa e ensino do mundo (KRISHTALKA; HUMPHREY, 2000; SANTOS, 2004; DUDERSTADT, 2007).

Para esta tarefa, compôs-se uma equipe com cinco servidores da instituição, aprovada na sua 1152 ${ }^{\mathrm{a}}$ Egrégia Congregação, como a Comissão de Elaboração do Regimento do Museu Nacional e sob a portaria no ${ }^{\circ} 2709$, publicada em 21 de novembro de 2019 (UNIVERSIDADE FEDERAL DO 
RIO DE JANEIRO, 2019b). A composição da equipe ficou aberta para a participação voluntária de qualquer pessoa de seu quadro funcional.

O método para a elaboração do novo regimento divide-se em duas etapas: pré-produção e produção. Este artigo aborda apenas os métodos referentes à etapa de pré-produção, única etapa concluída até o presente momento, e cujos resultados apontaram para os problemas apresentados no presente artigo referentes à estrutura universitária e à estrutura museal. Esta etapa constituiu-se de busca e análise de documentos e avaliação da realidade institucional do Museu Nacional/UFRJ.

A busca teve por objetivo recuperar os documentos pertinentes à elaboração do novo regimento, como aqueles que regulamentaram ou regeram o Museu Nacional ao longo de sua história, incluindo o Regimento atual de 1971; o Regimento e Estatuto atualizados da UFRJ; os Regimentos e Estatutos atualizados de outras unidades da UFRJ; as normativas de Congregações que complementam o Regimento de 1971 e o Estatuto de Museus (LEGISLAÇÃO..., 2017). A análise consiste em leitura crítica de todos os documentos, levantando dados para adequar o Regimento do Museu Nacional, enquanto museu universitário, a todas as regulamentações necessárias e atuais.

\subsection{Análise das estruturas museal e acadêmica}

Para esta avaliação foram analisadas as estruturas organizacionais do Museu Nacional (UNIVERSIDADE FEDERAL DO RIO DE JANEIRO, $1971 ; 2020)$, bem como aquelas previstas em regimentos publicados recentemente por museus do Instituto Brasileiro de Museus (Ibram), como Museu de Arte Religiosa e Tradicional de Cabo Frio, Museu Histórico Nacional, Museu do Diamante, Museu das Missões (BRASIL, 2018b; BRASIL, 2018a; BRASIL, 2019a; BRASIL, 2019b) e para as unidades acadêmicas da UFRJ,

previstas tanto em seu Estatuto (UNIVERSIDADE FEDERAL DO RIO DE JANEIRO 2019a), como no Regimento (UNIVERSIDADE FEDERAL DO RIO DE JANEIRO 2019c). Assim, as estruturas museal e acadêmica simplificadas foram sumarizadas em organogramas através do programa Lucidchart (LUCID SOFTWARE INC., 2020) e comparadas ao organograma simplificado do Museu Nacional.

Segundo o Estatuto da UFRJ (UNIVERSIDADE FEDERAL DO RIO DE JANEIRO 2019a), as unidades acadêmicas têm como fração mínima o 
departamento. Todavia, neste estatuto, os departamentos seriam compostos apenas por servidores docentes. Mas, na prática, os departamentos são compostos por servidores docentes e técnicos.

Com o objetivo de traçar o perfil atual dos servidores técnicos, alocados nos departamentos do Museu Nacional/UFRJ, fez-se o levantamento dos dados referentes a titulação, cargo, data de entrada, atuação na instituição e manutenção de currículo na Plataforma Lattes (CONSELHO NACIONAL DE DESENVOLVIMENTO CIENTÍFICO E TECNOLÓGICO, [s.d.]). Foi considerado para o critério titulação, os cursos em andamento como completos para os servidores que não extrapolaram o prazo, pois estima-se que a conclusão se dará brevemente. Esses dados foram organizados em planilha Excel (MICROSOFT, 2019), e os gráficos, com base nos números de funcionários, foram feitos no mesmo programa.

\subsection{Realidade institucional do Museu Nacional/UFRJ}

É importante analisar os dados acerca da complexidade organizacional do Museu Nacional/UFRJ descrita e compará-los com a realidade da instituição e sua comunidade em suas múltiplas características e funções.

Além disso, os aspectos levantados aqui foram coletados através de discussões entre os membros da comissão e em reuniões realizadas periodicamente com os diversos entes que compõem a comunidade do Museu Nacional e que também visam esclarecer dúvidas, atualizar conceitos e elencar sugestões para alterações no regimento da instituição.

Por meio deste procedimento, foram elencados alguns problemas práticos, causados pela atual estrutura organizacional e que são discutidos neste trabalho. São eles: a) composição dos departamentos e a representatividade do corpo técnico museal nos departamentos; b) a participação do corpo técnico museal em curadoria, ensino, pesquisa e extensão; e c) as demandas do Museu Nacional para a implementação de códigos próprios para disciplinas de graduação.

\section{RESULTADOS E DISCUSSÃO}

O histórico de publicação e atualização do regimento interno do Museu Nacional reflete mudanças pontuais de seu funcionamento, com o último regimento em voga publicado em 1971 (Quadro 1). 


\begin{tabular}{|c|c|c|c|}
\hline QUADRO 1 & Ano & Publicação & Objetivo \\
\hline \multirow{11}{*}{$\begin{array}{r}\text { Documentação } \\
\text { oficial que } \\
\text { regulamenta e/ou } \\
\text { regimenta o Museu } \\
\text { Nacional. Fonte: } \\
\text { elaborado pelos } \\
\text { autores. }\end{array}$} & 1818 & $\begin{array}{l}\text { Decreto } \\
\text { de 06/06/1818 }\end{array}$ & $\begin{array}{l}\text { Criação do Museu Real: } \\
\text { Crêa um Museu nesta Côrte, e manda que elle seja estabelecido em } \\
\text { um predio do Campo de Sant'Anna que manda comprar e incorporar } \\
\text { aos proprios da Corôa }\end{array}$ \\
\hline & 1842 & $\begin{array}{l}\text { Decreto n. } 123 \\
\text { de } 03 / 02 / 1842\end{array}$ & $\begin{array}{l}\text { Primeira organização: } \\
\text { Dá ao Museu Nacional uma organisação accommodada á melhor } \\
\text { classificação e conservação dos objectos }\end{array}$ \\
\hline & 1876 & $\begin{array}{l}\text { Decreto n. } 6.116 \\
\text { de } 09 / 02 / 1876\end{array}$ & $\begin{array}{l}\text { Primeira reorganização: } \\
\text { Reorganizar o Museu Nacional }\end{array}$ \\
\hline & 1888 & $\begin{array}{l}\text { Decreto n. } 9.942 \\
\text { de } 25 / 04 / 1888\end{array}$ & Segunda reorganização \\
\hline & 1910 & $\begin{array}{l}\text { Decreto n. } 7.862 \\
\text { de 09/02/1910 }\end{array}$ & Terceira reorganização \\
\hline & 1911 & $\begin{array}{l}\text { Decreto } n .9 .211 \\
\text { de } 15 / 12 / 1911\end{array}$ & Primeiro regulamento \\
\hline & 1916 & $\begin{array}{l}\text { Decreto n. } 11.896 \\
\text { de } 14 / 01 / 1916\end{array}$ & Segundo regulamento \\
\hline & 1931 & $\begin{array}{l}\text { Decreto n. } 19.801 \\
\text { de } 27 / 03 / 1931\end{array}$ & Terceiro regulamento \\
\hline & 1946 & $\begin{array}{l}\text { Decreto-lei n. } 8.689 \\
\text { de } 16 / 01 / 1946\end{array}$ & Incorporação à Universidade do Brasil \\
\hline & 1958 & $\begin{array}{l}\text { Publicação do Museu } \\
\text { Nacional, série C n.1 }\end{array}$ & Primeiro regimento \\
\hline & 1971 & $\begin{array}{l}\text { Separata do Boletim } \\
\text { n. } 32 \text { de } 12 / 08 / 1971\end{array}$ & Segundo Regimento \\
\hline
\end{tabular}

O decreto de 6 de junho de 1818 cria o Museu Real, localizado no Campo de Santana, na cidade do Rio de Janeiro. Porém, é o decreto de 1842 que estabelece de fato a forma de funcionamento do Museu, apresentando inclusive o valor dos vencimentos. Os decretos de 1876 a 1931 atualizam principalmente os valores de despesas com os vencimentos de pessoal, a estrutura de funcionamento, as categorias (e, por vezes, o quantitativo destas) e modifica a divisão em seções, ora reorganizando disciplinas, ora reorganizando a ordem das seções.

Em 1946, a partir da incorporação do Museu à Universidade do Brasil, atual Universidade Federal do Rio de Janeiro, os regimentos passaram a ter um caráter cada vez mais próximo de um regimento interno de uma unidade acadêmica universitária, diminuindo, em certos aspectos, o caráter museal do Museu Nacional. Apenas dois regimentos foram redigidos e/ou atualizados após a incorporação na UFRJ e datam de 1958 e 1971. 
Um ponto, em particular, chama a atenção: as categorias necessárias para o pleno funcionamento de um museu com acervo próprio figuram de forma compartimentalizada. No atual regimento do Museu Nacional, apenas a Seção de Museologia (SEMU) e a Seção de Assistência ao Ensino (SAE) claramente congregam corpo técnico dedicado às atividades museais. Os demais elementos, próprios de um museu, apresentam uma redação genérica, como no caso das coleções, que "terão pessoal qualificado para mantê-las e ampliá-las, bem como docentes responsáveis pelas mesmas" (UNIVERSIDADE FEDERAL DO RIO DE JANEIRO, 1971, p. 13).

\subsection{As estruturas museal e acadêmica}

Os museus geridos pelo Ibram são compostos por duas estruturas em termos de função específica: estrutura administrativa e estrutura museal (Figura $1 \mathrm{~A}$ ). A estrutura administrativa abarca as funções necessárias para a gestão e manutenção da instituição, enquanto a estrutura museal abrange todos os setores e profissionais ligados às coleções e exposições, atuando na conservação, manutenção, aquisição, mediação e pesquisa.

As unidades acadêmicas da UFRJ são compostas por duas estruturas principais: estrutura administrativa e estrutura acadêmica (Figura $1 \mathrm{~B}$ ). A estrutura administrativa abarca as funções necessárias para a gestão e manutenção da instituição, de modo análogo aos museus do Ibram. Por conseguinte, a estrutura acadêmica abrange todos os departamentos e profissionais, em sua maioria docentes, ligados às atividades de ensino, pesquisa e extensão.

A sumarização das estruturas museal e acadêmica em dois organogramas (Figuras $1 \mathrm{~A}$ e $1 \mathrm{~B}$ ) é um exercício para compreendermos os elementos necessários para o desenvolvimento das atividades fim, de ambos os tipos institucionais e compará-los ao atual organograma do Museu Nacional (Figura ${ }_{1 C}$ ).

Ao analisarmos a realidade das unidades acadêmicas na UFRJ (Figura 1B), constata-se que as estruturas administrativa e acadêmica não são completamente separadas; ao contrário, interagem, por exemplo, com a presença de elementos da estrutura administrativa dentro de departamentos (como as secretarias). 
FIGURA 1

A) Organograma simplificado das estruturas em museus

do Ibram (baseado

nos regimentos mais recentes, principalmente o Regimento Interno do Museu Histórico Nacional); B) Organograma simplificado das estruturas em unidades acadêmicas (UFRJ); C) Organograma simplificado das estruturas no Museu Nacional (UFRJ)

- Legenda: azul: estruturas museais; amarelo: estruturas acadêmicas: verde: estruturas museais e acadêmicas combinadas.

Fonte: elaborado pelos autores.
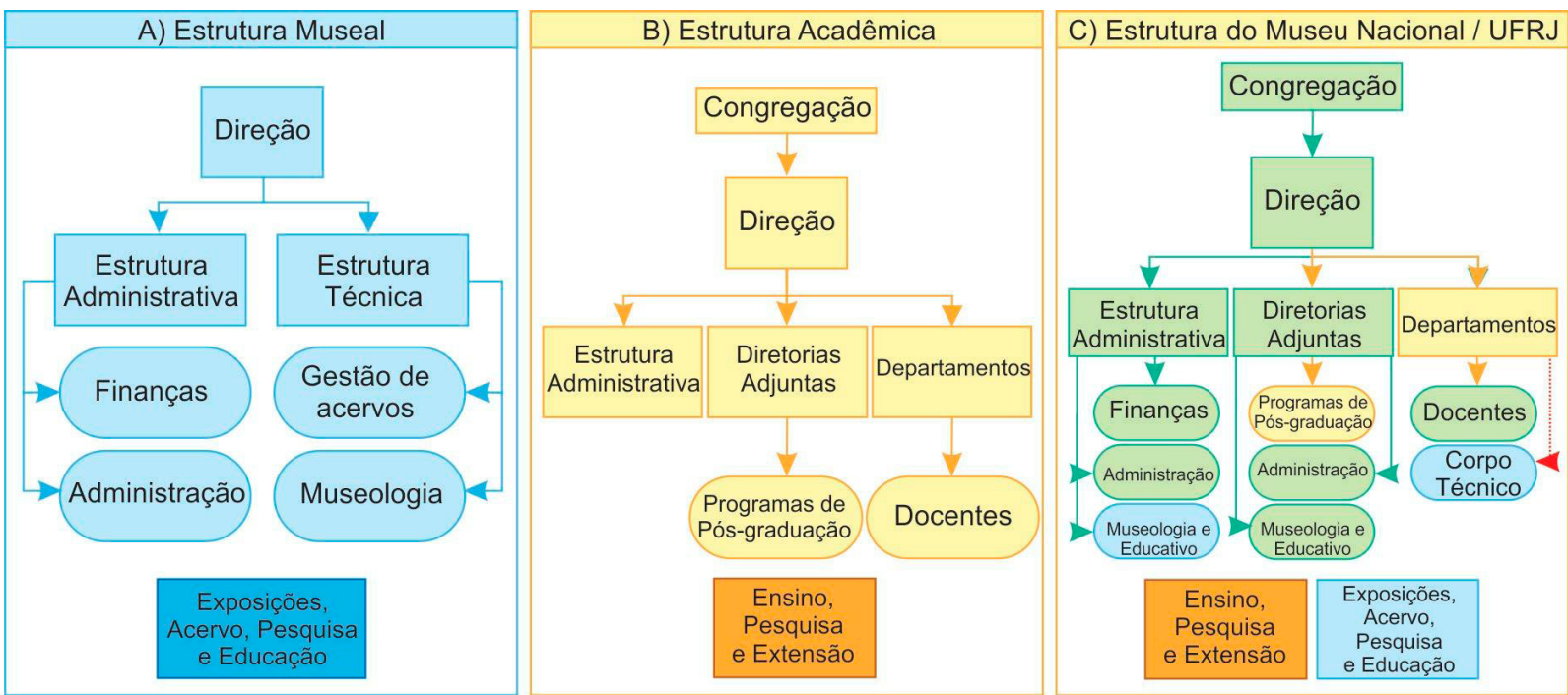

No tocante aos museus universitários, é esperado que as três estruturas estejam presentes. No caso do Museu Nacional percebemos em que medida tais estruturas estão presentes e relacionadas. $\mathrm{Na}$ Figura ${ }_{1} \mathrm{C}$, os elementos que têm em sua composição e/ou atividades tanto parte da estrutura museal como da estrutura acadêmica (em verde), atuam de forma uníssona dentro da perspectiva de um museu dentro de uma universidade. Já os elementos que desempenham funções ligadas apenas a uma das estruturas supracitadas (em azul e amarelo) permanecem com ideário compartimentalizado.

É possível notar que a estrutura administrativa atende de forma plena as demais estruturas, contribuindo para a manutenção das atividades museais e acadêmicas. No entanto, o corpo técnico ligado às atividades museais, como exposições e acervos, encontra-se aparentemente limitado a essas atividades. Em especial, nota-se sua atuação ligada aos acervos, os quais estão sob as diretrizes de departamentos (ver regimento do $\mathrm{MN}$, 1971). Estes, por conseguinte, devem seguir as normas estabelecidas na Lei de Diretrizes e Bases da Educação Nacional (LDB) (BRASIL, 1996).

\subsection{Perfil do corpo técnico museal}

O Museu Nacional abriga em seus departamentos quadro funcional técnico em diversos cargos, com níveis distintos de formação acadêmica. O Quadro 2 ilustra qualitativamente esta complexidade. 


\begin{tabular}{|c|c|c|}
\hline \multirow{6}{*}{$\begin{array}{r}\text { QUADRO 2 } \\
\text { Perfil qualitativo do } \\
\text { quadro funcional } \\
\text { dos servidores } \\
\text { técnicos de equipes } \\
\text { curatoriais (excluindo } \\
\text { o administrativo), } \\
\text { alocados em }\end{array}$} & Cargo & Formação \\
\hline & Arqueólogo & Mestrado, Doutorado e Especialização \\
\hline & Assistente de Laboratório & Ensino Médio, Graduação, Doutorado \\
\hline & Biólogo & Especialização, Mestrado, Doutorado \\
\hline & Gerente de Coleções & Mestrado e Doutorado \\
\hline & Historiador & Doutorado \\
\hline \multirow{8}{*}{$\begin{array}{r}\text { Departamentos no } \\
\text { Museu Nacional/ } \\
\text { UFRJ, indicando } \\
\text { a diversidade de } \\
\text { cargos existentes } \\
\text { e a formação dos } \\
\text { servidores nestes } \\
\text { cargos. Fonte: } \\
\text { elaborado pelos } \\
\text { autores. }\end{array}$} & Produtor Cultural & Graduação \\
\hline & Programador Visual & Graduação e Doutorado \\
\hline & Químico & Doutorado \\
\hline & Taxidermista & Ensino Médio, Mestrado \\
\hline & Técnico em Assuntos Educacionais & Doutorado \\
\hline & Técnico de Laboratório & $\begin{array}{l}\text { Ensino Médio, Graduação, Especialização, Mestrado, } \\
\text { Doutorado }\end{array}$ \\
\hline & $\begin{array}{l}\text { Técnico em Conservação / } \\
\text { Preparação de Fósseis }\end{array}$ & Graduação, Especialização, Mestrado e Doutorado \\
\hline & Técnico em Herbário & Ensino Médio e Graduação \\
\hline
\end{tabular}

Os seis departamentos do Museu Nacional alocam atualmente 79 técnicos (Tabela 1). Destes, 62 mantém currículo na Plataforma Lattes (CONSELHO NACIONAL DE DESENVOLVIMENTO CIENTÍFICO E TECNOLÓGICO, [s.d.]) e 17 não mantém. Segundo a formação desses técnicos, tem-se $11 \mathrm{com}$ Ensino Médio, 13 graduados, 6 especialistas, 17 mestres, 27 doutores, e 5 sem informação disponível.

Quando observada a distribuição dos técnicos nos departamentos (Tabela 1, Gráfico 1), observa-se que o Departamento de Antropologia detém o corpo técnico com o maior número de pós-graduados da instituição, totalizando 17 servidores. Ele é seguido pelo Departamento de Geologia e Paleontologia, com 11; Departamento de Botânica, 9; Departamento de Vertebrados, 7; Departamento de Invertebrados, 4 e Departamento de Entomologia, 2.

TABELA 1

\begin{tabular}{|c|c|c|c|c|c|c|c|c|c|}
\hline \multirow[t]{2}{*}{ Formação } & \multicolumn{7}{|c|}{ Departamentos } & \multicolumn{2}{|c|}{ Currículo Lattes } \\
\hline & DA & DB & $\mathrm{DE}$ & DGP & DI & DV & Total & Sim & Não \\
\hline Ensino Médio & 0 & 3 & 0 & 1 & 2 & 5 & 11 & 0 & 16 \\
\hline Graduação & 3 & 3 & 2 & 4 & 1 & 0 & 13 & 12 & 1 \\
\hline Especialização & 2 & 1 & 0 & 1 & 1 & 1 & 6 & 6 & 0 \\
\hline Mestrado & 6 & 4 & 0 & 4 & 1 & 2 & 17 & 17 & 0 \\
\hline Doutorado & 9 & 4 & 2 & 6 & 2 & 4 & 27 & 27 & 0 \\
\hline Não informado & 3 & 1 & 0 & 0 & 1 & 0 & 5 & 0 & 5 \\
\hline Total & 23 & 16 & 4 & 16 & 8 & 12 & 79 & 62 & 17 \\
\hline
\end{tabular}


Perfil dos servidores técnicos, alocados nos Departamentos do Museu Nacional/UFRJ.

Indicando no eixo y o número de técnicos-

administrativos e no eixo

$x$, a formação e alocação nos departamentos. Sendo

DA - Departamento

de Antropologia, DB -

Departamento de Botânica,

DE - Departamento

de Entomologia, DGP

- Departamento de

Geologia e Paleontologia,

DI - Departamento

de Invertebrados

DV - Departamento de

Vertebrados; EM - Ensino

Médio, ? - Não informado.

Fonte: elaborado pelos autores.

TABELA 2

Perfil dos servidores técnicos, alocados nos Departamentos do Museu Nacional/UFRJ. Indicando o número de técnicos pela data de entrada, tempo de serviço e formação.

Sendo, E.M. - Ensino Médio, Grad. - Graduação, Esp. - Especialização Mest. - Mestrado Dout. - Doutorado e N.I. - não informado. Fonte: elaborada pelos autores.

\begin{tabular}{|c|c|c|c|c|c|c|c|c|}
\hline Data de entrada & Tempo de serviço (anos) & $E M$ & Grad. & Esp. & Mest. & Dout. & N.I. & Total \\
\hline anterior a 1979 & acima de 41 & 1 & 0 & 0 & 1 & 0 & 0 & 2 \\
\hline $1980-1984$ & 36 a 40 & 0 & 0 & 1 & 1 & 0 & 1 & 3 \\
\hline $1985-1989$ & 31 a 35 & 1 & 2 & 1 & 0 & 2 & 1 & 7 \\
\hline $1990-1994$ & 26 a 30 & 1 & 1 & 1 & 2 & 2 & 2 & 9 \\
\hline $1995-1999$ & 21 a 25 & 0 & 0 & 0 & 0 & 0 & 0 & 0 \\
\hline $2000-2004$ & 16 a 20 & 0 & 0 & 0 & 0 & 0 & 0 & 0 \\
\hline $2005-2009$ & 11 a 15 & 0 & 1 & 1 & 1 & 1 & 0 & 4 \\
\hline $2010-2014$ & 6 a 10 & 0 & 2 & 1 & 4 & 9 & 1 & 17 \\
\hline $2015-2019$ & 1 a 5 & 1 & 6 & 1 & 8 & 13 & 0 & 29 \\
\hline Total & & 4 & 12 & 6 & 17 & 27 & 5 & 71 \\
\hline
\end{tabular}




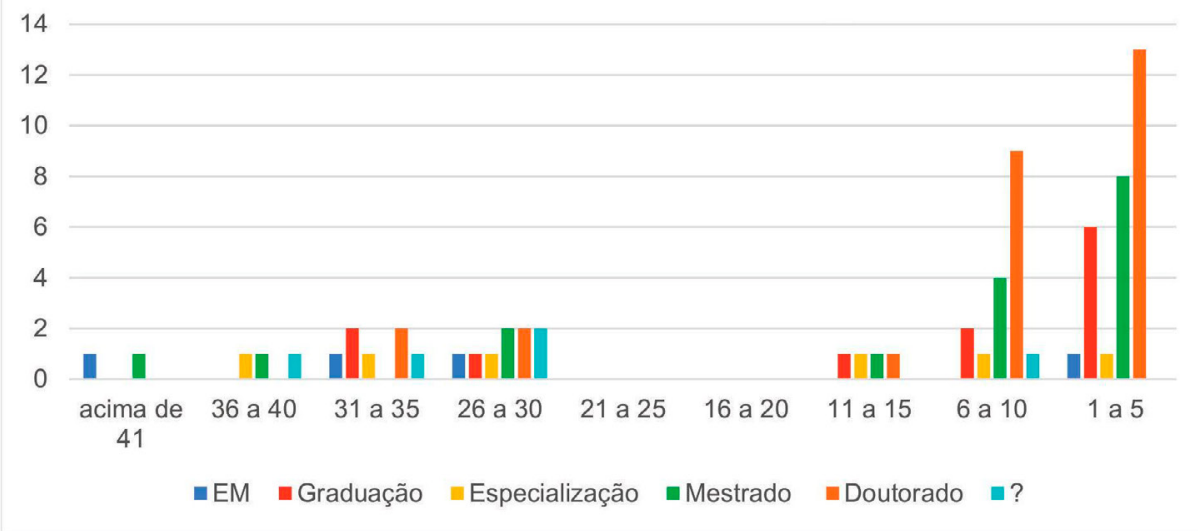

Pelo perfil deste corpo técnico - 50 servidores são pós-graduados, sendo que 36 ingressaram nos últimos dez anos, a maioria mantendo um currículo na Plataforma Lattes (CONSELHO NACIONAL DE DESENVOLVIMENTO CIENTÍFICO E TECNOLÓGICO, [s.d.]) -, fica evidente que esses servidores mantêm interesse pela realização das atividades relacionadas ao ensino, pesquisa e extensão, independentemente do cargo ocupado na instituição. É necessária a reflexão coletiva para o melhor aproveitamento de todos os servidores, em prol de uma instituição mais dinâmica e plural.

\subsection{Composição dos departamentos e a representatividade do corpo técnico museal}

Na LDB (BRASIL, 1996) o princípio da gestão democrática é obrigatório para as instituições de nível superior:

Art. $56^{\circ}$. As instituições públicas de educação superior obedecerão ao princípio da gestão democrática, assegurada a existência de órgãos colegiados deliberativos, de que participarão os segmentos da comunidade institucional, local e regional.

Parágrafo único. Em qualquer caso, os docentes ocuparão setenta por cento dos assentos em cada órgão colegiado e comissão, inclusive nos que tratarem da elaboração e modificações estatutárias e regimentais, bem como da escolha de dirigentes.

Esta obrigatoriedade é traduzida no Estatuto da UFRJ (UNIVERSIDADE FEDERAL DO RIO DE JANEIRO, 2019a) como: 
Art. 15. A Universidade Federal do Rio de Janeiro constitui-se dos seguintes conjuntos de órgãos:

I - órgãos da Infra-estrutura; II - órgãos da Estrutura Média; e III órgãos da Estrutura Superior.

Parágrafo único. Os órgãos colegiados, da Estrutura Superior, dos Centros e das Unidades Universitárias, deverão obedecer ao princípio da gestão democrática, com representação docente de no mínimo 70\% (setenta por cento) e a garantia de participação de discentes, técnico-administrativos, antigos alunos e membros da comunidade externa, como previsto na legislação vigente.

Em relação ao corpo deliberativo dentro do departamento, o Estatuto apresenta como composição:

Art. 21. O Corpo Deliberativo é composto pelos professores Titulares, professores Associados, professores Adjuntos e professores contratados a esses níveis, além de um representante dos professores Assistentes, Auxiliares e contratados nestes mesmos níveis, representantes do Corpo Discente, eleitos entre os alunos das disciplinas compreendidas no Departamento, e representantes do Corpo Técnico-Administrativo, na forma da legislação vigente. (Redação dada pela Resolução CONSUNI no $03 / 2009)$.

Nota-se nesta redação que o princípio da gestão democrática, o qual deve contar com "segmentos da comunidade institucional, local e regional" rege somente as instâncias superiores de deliberação e não se estende às instâncias de infraestrutura e estrutura média deliberativas. O corpo deliberativo de um departamento apenas debate e aprova para encaminhamento questões, propostas e elementos do cotidiano profissional às instâncias superiores, tais como o conselho departamental e a congregação da unidade universitária. Assim, se a obrigatoriedade de representação docente de no mínimo $70 \%$ não cabe no nível departamental, cabe analisar em que medida funciona a atuação do corpo técnico-administrativo no departamento de forma a sua presença no corpo deliberativo ser limitada à representação.

Nesse sentido, vemos no artigo inicial Seção I (Dos Departamentos), do Capítulo II (Da Infraestrutura), que não há lotação prevista de corpo técnico ou administrativo:

Art. 19. O Departamento, menor fração da estrutura da Universidade Federal do Rio de Janeiro, para os efeitos de organização administrativa, 
didático-científica e de distribuição de pessoal, compreende disciplinas afins e congrega professores para objetivo comum de ensino, pesquisa e extensão.

A composição prevista dos departamentos é apenas de docentes. O Regimento da UFRJ (elaborado em 1970, revisado em 2019) - no qual uma parte da redação replica o que já existe no Estatuto -, no capítulo sobre os departamentos, há apenas duas menções à categoria diferente à categoria docente:

Art. $2^{\circ}$ - Ao Departamento, constituído na forma do Art. 19 do Estatuto, compete:

$(\ldots)$

$\mathrm{V}$ - propor a admissão, a transferência e o afastamento do pessoal docente e administrativo;

(...)

Art. $4^{\circ}$ - Ao Chefe de Departamento compete:

(...)

VI - controlar a freqüência dos servidores técnicos e administrativos;

Ainda, em relação ao corpo deliberativo, nem mesmo um representante técnico-administrativo é previsto:

Art. $3^{\circ}$ - O Departamento é dirigido por um Chefe, designado pelo Diretor da Unidade, mediante prévia indicação do seu Corpo Deliberativo, consoante as normas estabelecidas no art. 20 do Estatuto.

$\$ 1^{\circ}-$ O Corpo Deliberativo é constituído pelos professores titulares e adjuntos e docentes contratados a esses níveis, de um representante dos professores assistentes e de um dos contratados a esse nível, bem como de um representante do corpo discente, eleito dentre os alunos das disciplinas compreendidas no Departamento.

Dessa forma, é possível perceber que tal redação parte do princípio lançado no Estatuto no qual o departamento "congrega professores para objetivo comum de ensino, pesquisa e extensão". O corpo técnico-administrativo, denominado no Regimento apenas como administrativo, não aparece como parte do departamento, mas como elemento fortuito.

No Estatuto há apenas uma breve descrição de caracterização sobre o corpo técnico-administrativo: 


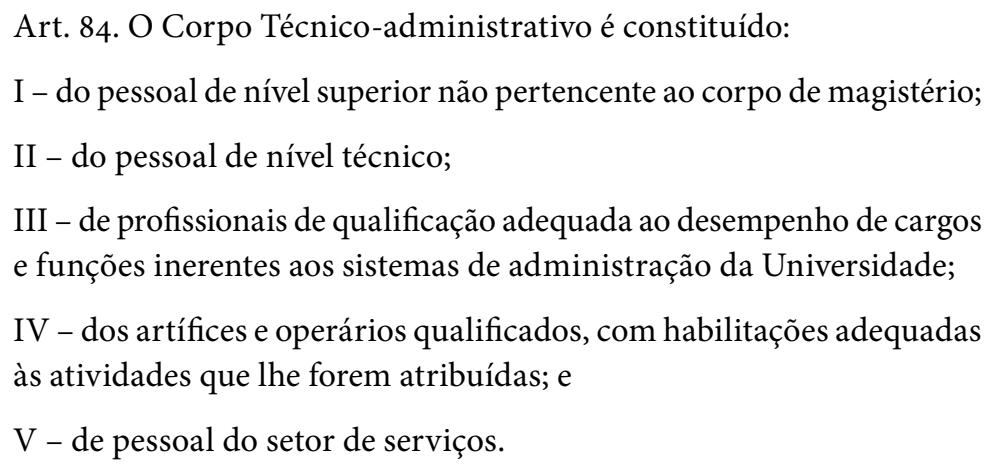

No Regimento da UFRJ, menos atualizado, há a distinção entre corpo técnico e corpo administrativo, com cada tipo tendo capítulo próprio. Todavia, a redação se limita a regulamentar o tipo de entrada na instituição com duas categorias: a) pessoal do Quadro Único; e b) pessoal contratado.

Assim, se o corpo técnico museal ligado diretamente à direção, como a Seção de Museologia, a Seção de Assistência ao Ensino e o Núcleo de Atendimento ao Público (NAP), formalmente pode conduzir o cotidiano em seus respectivos setores, com participação e voz plena, o mesmo não pode ser dito sobre o corpo técnico museal lotado nos departamentos. Majoritariamente, os acervos do Museu Nacional estão sob a responsabilidade dos departamentos, seguindo de forma temática e disciplinar a curadoria das coleções. O corpo técnico ligado diretamente a estas coleções é composto por profissionais diversos e qualificados, como biólogos, arqueólogos e tecnólogos/ gerentes de coleções, que desempenham papel fundamental para sua manutenção, conservação, pesquisa e acesso público. No entanto, a participação limitada à representação no corpo deliberativo do Departamento leva-nos a questionar a agência deste corpo técnico e a possibilidade de atuação e cumprimento pleno de suas funções. Por conseguinte, dessa forma, a estrutura museal estaria também limitada em sua atuação e realização.

\subsection{Participação do corpo técnico museal em curadoria, ensino, pesquisa e extensão}

Considerando a qualificação de boa parte do corpo técnico dedicado ao acervo, seria esperado que a compatibilização entre as estruturas em determinados elementos fosse patente. No tocante à coordenação e execução de projetos de extensão, essa é uma realidade de sucesso, já que a universidade e o museu permitem que técnicos possam coordenar ações de 
extensão. No entanto, em relação aos programas de pós-graduação, dos seis programas, apenas o de Pós-Graduação em Geociências - Patrimônio Geopaleontológico (PPGEO) conta com servidores de carreira técnica credenciados em seu corpo docente. De acordo com a Resolução CEPG n ${ }^{\circ} 1$ de 2006, de $1^{\circ}$ de dezembro de 2006, os funcionários técnico-administrativos da Universidade Federal do Rio de Janeiro com título de doutor e competência reconhecida pelo programa de pós-graduação podem fazer parte do corpo docente de um programa de pós-graduação, sem alterar o vínculo funcional preexistente (UNIVERSIDADE FEDERAL DO RIO DE JANEIRO, 2006).

A possibilidade de participação do corpo técnico museal em programas de pós-graduação pode promover um maior entrelaçamento entre a estrutura museal e a acadêmica. Considerando que a pesquisa e a educação são pilares de uma instituição museal, os programas de pós-graduação mostram-se como mais um espaço propício para atuação desta categoria, contribuindo especialmente em relação aos acervos e a sua experiência no cotidiano curatorial. Da mesma forma, campos específicos dessa vivência profissional poderiam ser aprofundados no tocante à formação e especialização de novos profissionais, como nas áreas da museologia e do patrimônio material e imaterial.

Considerando a sinergia a partir da parceria com ambas as categorias funcionais presentes em um museu universitário, a docente e a técnica, é possível vislumbrar programas, principalmente de lato sensu, que se dediquem à formação de profissionais voltados para atuação em museus. No entanto, outro sintoma de descompasso é revelado, uma vez que obrigatoriamente todo programa de pós-graduação deve ter maioria da categoria docente. Em geral, essa obrigatoriedade não causa impacto, mas em um museu universitário, áreas específicas, como a museologia, não contam com um corpo docente, apenas com um corpo técnico especializado.

No tocante à curadoria e gerenciamento dos acervos, apesar de recente acréscimo no número de pessoal para compor o corpo técnico com ênfase nos acervos, como os gerentes de coleção, a atuação destes se encontra limitada, uma vez que assuntos relacionados às coleções são discutidos em reuniões de conselhos deliberativos de departamento, cuja representação técnico-administrativa é restrita, conforme supracitado. 
3.5 Demandas do Museu Nacional para a implementação de códigos próprios para disciplinas de graduação

Outro sintoma do descompasso entre as estruturas acadêmica e museal reflete-se na atuação de docentes no ensino de graduação dentro da UFRJ. Pois o Museu Nacional, ligado ao Fórum de Ciência e Cultura, não oferece cursos de graduação. Assim, a atuação dos servidores no ensino formal é focada principalmente nos programas de pós-graduação.

A participação em cursos de graduação é por meio de parcerias com outras unidades acadêmicas da UFRJ, assumindo ou colaborando em disciplinas registradas e administradas nessas unidades, fora do Museu Nacional.

Considerando a função de um museu universitário de atender a comunidade interna e externa à universidade, mostra-se salutar que este também possa registrar e administrar disciplinas do nível de graduação, mesmo que não tenha cursos de graduação. A autonomia para registrar e administrar disciplinas eletivas possibilitaria atingir de forma mais consistente a comunidade interna no nível da graduação, com disciplinas de caráter acadêmico e museal, incluindo atividades práticas afinadas com os diferentes momentos do Museu. Isto também melhoraria a integração do Museu Nacional à UFRJ e traria com maior facilidade alunos de graduação interessados em desenvolver iniciação científica nos diversos campos de atuação da instituição.

\section{CONSIDERAÇÕES FINAIS}

Com este modelo, é possível vislumbrar que museus universitários são compostos por três estruturas: administrativa (similar em museus e universidades), acadêmica e museal. Dessa forma, cabe debater e compreender coletivamente em que medida essas estruturas estão presentes no Museu Nacional, e em museus universitários de forma geral, a fim de promover, de fato, a realização plena de todas as estruturas e, por conseguinte, de todas as atividades fim esperadas. É necessário, nesse sentido, partir do princípio que um museu universitário não pode ser uma simples soma de suas partes, facilmente destacadas, mas que a sinergia dessas as tornem indissociáveis.

A presença de técnicos apenas por representação em determinados espaços demonstra que uma estrutura universitária centrada na existência de apenas duas categorias, docentes e técnicos, relegando a participação 
de uma delas apenas a representação em conselhos deliberativos, de acordo com o estabelecido pelo estatuto da UFRJ, não reflete a complexidade de um museu e sua diversidade de profissionais, já que grande parte da estrutura museal se encontra na categoria de técnicos. Essa conformação de conselhos deliberativos acaba gerando um viés e estabelecendo uma cultura que acarreta outros tipos de situações peculiares, por exemplo, o estabelecimento no regimento do Museu Nacional de que a chefia da Comissão de Exposições deve ser necessariamente exercida pelo Diretor Adjunto de Ensino, mesmo que fosse mais salutar que profissionais do setor responsável pelas exposições ou com trajetória análoga reconhecida ocupassem essa posição.

Esse exemplo se encaixa bem em uma das problemáticas de museus universitários nacionais e internacionais citadas por Smania-Marques e Lira-da-Silva, (2011), que são as chefias exercidas por pessoas sem formação ou experiência na área museológica ou em atividades relacionadas a acervos em instâncias estratégicas do ponto de vista museal. Outros museus universitários ainda podem sofrer de algo mais drástico, em que há total falta de profissionais especializados em atividades museológicas.

Apesar de um corpo técnico diversificado e qualificado, como demonstrado aqui, que contou com um certo acréscimo nos últimos anos, como a criação do cargo de gerente de coleção, pode-se afirmar que o Museu Nacional ainda sofre com a defasagem de pessoal especializado para trabalhar com seus acervos e atividades relacionadas a estes.

Um outro exemplo de como a estrutura acadêmica acaba se estendendo em múltiplos aspectos, além daqueles reguladas pelo estatuto e regimento da universidade, é que recentemente, com o esforço de formulação das políticas de coleção do Museu Nacional, foi marginalmente levantada a questão de que esse processo deveria ser protagonizado por docentes, quando na verdade a literatura indica que a melhor forma de conduzir esse processo em museus é através do envolvimento da maior diversidade dos profissionais que trabalham ali (SIMMONS, 2017).

Programas de pós-graduação que não permitem o credenciamento dos demais profissionais de museus não aproveitam a estrutura museal onde estão inseridos e não se distinguem de programas semelhantes de outras unidades acadêmicas não museais, fazendo com que o museu não 
cumpra plenamente sua função de formar pessoas voltadas para atuar em tais instituições, sendo este também um exemplo do estrangulamento da estrutura museal em detrimento da acadêmica.

Destarte, propomos a caracterização e implementação de uma estrutura museal-acadêmica, na qual todas as categorias funcionais de servidores públicos envolvidas possam desempenhar plenamente as atividades necessárias para a manutenção e crescimento do museu universitário em questão. Dessa forma, aqueles que seriam originalmente entendidos como parte da estrutura universitária acadêmica poderiam contribuir com as funções e atividades museais, como atividades curatoriais, e aqueles que seriam originalmente entendidos como parte da estrutura museal poderiam contribuir com as funções e atividades universitárias acadêmicas.

Um museu universitário, dentro desta perspectiva, cumpriria plenamente seu papel como museu, segundo a definição de Lourenço (2019), sem distinção de um museu não universitário. Lourenço lembra, ainda, que:

University museums, collections and heritage need good professionals, solid management tools - good definitions of museums, collections, archives - and integrated approaches to face the intrinsic volatility of the university and simultaneously enable them to tell unique stories about the complex, ugly, painstaking, difficult and often dark human endeavour of knowing about nature, the universe and about ourselves. This is their cultural contribution to society (2019, p. 4). ${ }^{2}$

Em que pese a particularidade da inserção do museu universitário dentro de um ambiente acadêmico universitário, este museu deve cumprir seu papel como parte da instituição universitária, contribuindo de forma ativa e propositiva no âmbito dos três eixos: ensino, pesquisa e extensão. Assim, se a definição de museu universitário não deve ser diferente da definição de museu, devemos, no entanto, entender que, sob a égide das normas de uma instituição universitária, o caráter museal pode não estar contemplado de modo que respeite e observe a definição internacional de museu.

2 Tradução livre: Museus universitários, coleções e patrimônio necessitam de bons profissionais, instrumentos sólidos de gestão - boas definições de museus, coleções, arquivos - e abordagens integradas para encarar a volatilidade intrínseca da universidade e simultaneamente habilitá-los a contar histórias singulares sobre o complexo, feio, doloroso, difícil e amiúde sombrio esforço humano para compreender a natureza, o universo e nós mesmos. Esta é sua contribuição cultural para a sociedade. 
Como corolário, encontramos então esse descompasso entre as estruturas, que limita o caráter museal do museu universitário, restringindo o foco principalmente no produto ou serviço, as exposições, e alijando os alicerces necessários para sua realização plena como instituição museal.

O diferencial de um museu universitário, para que cumpra seu propósito tanto museal como universitário, se encontra na necessidade da compatibilização e sintonia entre ambas as estruturas. Torna-se necessário entendê-las, no âmbito da universidade, como indissociáveis para que, assim, todo o quadro funcional possa atuar de forma plena e colaborativa, em prol de um museu diverso, dinâmico, plural, em diálogo aberto com a universidade e a sociedade, pronto para enfrentar os novos paradigmas do século XXI.

\section{REFERÊNCIAS}

ABSOLON, Bruno Araujo; FIGUEIREDO, Francisco José; GALLO, Valéria. O primeiro Gabinete de História Natural do Brasil ("Casa dos Pássaros") e a contribuição de Francisco Xavier Cardoso Caldeira. Filosofia e História da Biologia, v. 13, n. 1, p. 1-22, 2018. Disponível em: http://www.abfhib.org/FHB/FHB-13-1/FHB-v13-n1-o1.html. Acesso em: 29 jul. 2020.

ALMEIDA, Adriana Mortara. Museus e coleções universitários: por que museus de arte na Universidade de São Paulo? 2001. Tese (Doutorado em Ciências da Informação e Documentação) - Escola de Comunicações e Artes, Universidade de São Paulo, São Paulo, 2001.

BRASIL. Decreto de 6 de junho de 1818. Crêa um Museu nesta Côrte, e manda que elle seja estabelecido em um predio do Campo de Santa' Anna que manda comprar e incorporar aos proprios da Corôa. Coleção de Leis do Império do Brasil - 1818. Rio de Janeiro: Imprensa Nacional, 1889. v.1 Disponível em: https://www2.camara.leg.br/atividade-legislativa/legislacao/ colecao-anual-de-leis/copy_of_colecao1.html. Acesso em: 6 jun. 2020.

BRASIL. Decreto n. 19.444, de $1^{\circ}$. de dezembro de 1930. Dispõe sobre os serviços que ficam e cargo do Ministério da Educação e Saude Pública, e dá outras providências. Diário Oficial da União, Brasília, DF, Seção 1, p. 22907, 25 dez. 1930. Disponível em: https://www2.camara.leg. br/legin/fed/decret/1930-1939/decreto-19444-1-dezembro-1930-506386-publicacaooriginal-1-pe. html. Acesso em: 29 jul. 2020.

BRASIL. Lei n. 11.091, de 12 de janeiro de 2005. Dispõe sobre a estruturação do Plano de Carreira dos Cargos Técnico-Administrativos em Educação. Brasília, DF: Presidência da República, 2005a. Disponível em: http://www.planalto.gov.br/ccivil_03/_ato2004-2006/2005/lei/l11091. htm. Acesso em: 29 jul. 2020.

BRASIL. Lei n.12.772, de 28 de dezembro de 2012.Dispõe sobre a estruturação do Plano de Carreiras e Cargos de Magistério Federal. Brasília, DF: Presidência da República, 2012. Disponível em: http://www.planalto.gov.br/ccivil_03/_ato2011-2014/2012/lei/l12772.htm. Acesso em: 29 jul. 2020. 
BRASIL. Lei n. 5.540, de 28 de novembro de 1968. Fixa normas de organização e funcionamento do ensino superior e sua articulação com a escola média, e dá outras providências. Brasília, DF: Presidência da República, 1968. Disponível em: http://www.planalto.gov.br/ccivil_03/leis/L5540. htm. Acesso em: 29 jul. 2020.

BRASIL. Lei n. 9.394, de 20 de dezembro de 1996. Estabelece as diretrizes e bases da educação nacional. Disponível em: http://www.planalto.gov.br/ccivil_03/leis/l9394.htm Acesso em: 6 jun. 2020.

BRASIL. Ministério da Cidadania. Instituto Brasileiro de Museus. Portaria n. 65, de 22 de fevereiro de 2018. Anexo. Diário Oficial da União, Brasília, DF, ed. 37, Seção 1, p. 48-50, 23 fev.2018a.Disponível em: http://www.in.gov.br/web/guest/materia/-/asset_publisher/ KujrwoTZC2Mb/content/id/4203506/do1-2018-02-23-portaria-n-65-de-22-de-fevereirode-2018-4203502. Acesso em: 27 jul 2020.

BRASIL. Ministério da Cidadania. Instituto Brasileiro de Museus.Portaria n. 127, de o1 de abril de 2019. Aprova o Regimento Interno do Museu do Diamante - MD. Diário Oficial da União, Brasília, DF, ed. 63, Seção 1, p. 4, 2 abr. 2019a. Disponível em: http://www.in.gov.br/web/guest/ materia/-/asset_publisher/KujrwoTZC2Mb/content/id/69660190/do1-2019-04-02-portaria-n127-de-1-de-abril-de-2019-69660156. Acesso em: 27 jul. 2020.

BRASIL. Ministério da Cidadania. Instituto Brasileiro de Museus. Portaria n. 128, de o1 de abril de 2019b. Aprova o Regimento Interno do Museu das Missões - MM. Diário Oficial da União, Brasília, DF, ed. 63, Seção 1, p.5, 2 abr. 2019. Disponível em: http://www.in.gov.br/web/guest/ materia/-/asset_publisher/KujrwoTZC2Mb/content/id/69660187/do1-2019-04-02-portaria-n128-de-1-de-abril-de-2019-69660145. Acesso em: 27 jul. 2020.

BRASIL. Ministério da Cidadania. Instituto Brasileiro de Museus. Portaria n. 282, de 30 de julho de 2018b. Aprova o Regimento Interno do Museu de Arte Religiosa e Tradicional de Cabo Frio - MART. Diário Oficial da União, Brasília, DF, ed. 147, Seção 1, p.22, 1º. ago. 2018. Disponível em: http://www.in.gov.br/materia/-/asset_publisher/KujrwoTZC2Mb/content/ id/34930145/do1-2018-o8-o1-portaria-n-282-de-30-de-julho-de-2018-34930135. Acesso em: 27 jul. 2020 .

BRASIL. Ministério da Educação. Ofício Circular n. 015/2005/CGGP/SAA/SE/MEC. Brasília, DF: Ministério da Educação, 28 nov. 2005. Disponível em: http://portal.mec.gov.br/arquivos/pdf/ canalcggp/oficios/oc01505.pdf. Acesso em: 6. jun. 2020.

CONSELHO NACIONAL DE DESENVOLVIMENTO CIENTÍFICO E TECNOLÓGICO.

Plataforma Lattes. [s.d.]. Disponível em: lattes.cnpq.br. Acesso em: 29 jul. 2020.

DUARTE, Luiz Fernando Dias. O Museu Nacional: ciência e educação numa história institucional brasileira. Horizontes Antropológicos, n. 53, p. 359-384, 2019. Disponível em: http:// journals.openedition.org/horizontes/3041. Acesso em: 24 maio 2020.

DUDERSTADT, James J. Higher Education in the 21st Century: Global Imperatives, Regional Challenges, National Responsibilities, and Emerging Opportunities. Deep Blue, Michigan University, EUA. 2007. Disponível em: https:/deepblue.lib.umich.edu/bitstream/ handle/2027.42/88789/2007_Glion_VI_Duderstadt.pdf?sequence=1. Acesso em: 29 jul. 2020.

FERNANDES, Antonio Carlos Sequeira; CARVALHO, Marcelo de Araujo; ALMEIDA, Daianne; WITOVISK, Luciana. O Museu Nacional, suas análises de carvão mineral e a coleção de fósseis vegetais carboníferos no século XIX. Filosofia e História da Biologia, v. 9, n. 1, p. 1-18, 2014. Disponível em: http://www.abfhib.org/FHB/FHB-09-1/FHB-9-1-o1-Antonio-CarlosFernandes_Carvalho_Almeida_Witovski.pdf. Acesso em: 29 jul. 2020. 
FONTAINHA, Fernando de Castro; BARROS, Pedro Heitor; VERONESE, Geraldo Alexandre; ALVES, Camila Souza; FIGUEIREDO, Beatriz Helena; Waldburger, Joana. Processos seletivos para a contratação de servidores públicos: Brasil, o país dos concursos?: relatório de pesquisa Direito Rio. Rio de Janeiro, 2014.

INTERNATIONAL COUNCIL OF MUSEUMS. Icom code of ethics for museums. 2017. Disponível em: https://Icom.museum/wp-content/uploads/2018/o7/Icom-code-En-web.pdf. Acesso em: 28 jul. 2020.

INTERNATIONAL COUNCIL OF MUSEUMS. Standing committee for museum definition, prospects and potentials (MDPP). 2018. Disponível em: https://Icom.museum/wp-content/ uploads/2019/o1/MDPP-report-and-recommendations-adopted-by-the-Icom-EB-

December-2018_EN-2.pdf. Acesso em: 28 jul. 2020.

LACERDA, João Batista de. Fastos do Museu Nacional. Rio de Janeiro: Imprensa Nacional, 1905.

LEGISLAÇÃO sobre museus: Lei n. 11.904, de 14 de janeiro de 2009, que institui o Estatuto de Museus, Lei n. 11.906, de 20 de janeiro de 2009, que cria o Instituto Brasileiro de Museus (Ibram), e legislação correlata. 3. ed. Brasília, DF: Edições Câmara, 2017. Disponível em: http://bd.camara.gov.br/bd/bitstream/handle/bdcamara/14599/legislacao_museus_3ed. pdf?sequence $=15$. Acesso em: 29 jul. 2020 .

KRISHTALKA, Leonard; HUMPHREY, Philip S. Can Natural History Museums Capture the Future? BioScience, v. 50, n.7, p. 611-617, 200o. Disponível em: https://academic.oup.com/ bioscience/article/50/7/611/354777. Acesso em: 29 jul. 2020.

LOURENÇO, Marta. Defining the university museum today: Between Icom and the 'third mission'. Discurso proferido no encontro 'Il museo in evoluzione verso una nuova definizione', organizado pelo Icom Itália e Universidade de Milão, em 8 de maio de 2019. Disponível em: http://umac.Icom.museum/wp-content/uploads/2019/05/Lourenco_speech_Milan.pdf. Acesso em: 9 jun 2020.

LUCID Software Inc. Lucidchart. Software on-line de diagramas e comunicação visual. 2020. Disponível em: https://www.lucidchart.com/pages/pt. Acesso em: 23 jul. 2020.

MENDONÇA, Lúcia Glicério. Museus universitários e modernidade líquida: compromissos, desafios e tendências (um estudo sob a perspectiva da Teoria Ator-Rede, Brasil e Portugal). Tese de Doutorado. Universidade do Porto, 2017.

MICROSOFT. Microsoft 365 - Excel. 2019. Disponível em: https://www.microsoft.com/pt-br/ microsoft-365. Acesso em 29 jul. 2020.

PESSOA, Nara da Cunha. O Museu está vivo (?) O momento atual do Museu Câmara Cascudo. In: IV ENECULT - ENCONTRO DE ESTUDOS MULTIDISCIPLINARES EM CULTURA. Faculdade de Comunicação, UFBA, Salvador, Bahia, Brasil. 2008. Disponível em: http://www. cult.ufba.br/enecult20o8/14172.pdf. Acesso em: 28 jul. 2020.

RIBEIRO, Adelia Miglievich Ribeiro. Revisitando o Museu Nacional e a história da antropologia no Brasil pelas mãos de Heloísa Alberto Torres. Política \& Sociedade, v. 18, n. 41, p. 27-59, 2019. Disponível em: https://periodicos.ufsc.br/index.php/politica/article/viewFile/21757984.2019v18n41p27/40906. Acesso em: 28 jul. 2020.

RIBEIRO, Emanuela Sousa. Museus em universidades públicas: entre o campo científico, o ensino, a pesquisa e a extensão. Museologia e Interdisciplinaridade, v. 2, n. 4, p. 88-102, 2013. Disponível em: https://periodicos.unb.br/index.php/museologia/article/view/16366. Acesso em: 29 jul. 2020. 
SANTOS, Boaventura de Sousa. A Universidade no século XXI: para uma reforma democrática e emancipatória da Universidade. In: IV ENCONTRO INTERNACIONAL DO FÓRUM PAULO FREIRE, Porto, Portugal, 2004. Disponível em: http://www.acervo.paulofreire. org:808o/jspui/handle/7891/3915. Acesso em: 29 jul. 2020.

SIMÃO, Lucieni de Menezes. Elos do patrimônio: Luiz de Castro Faria e a preservação dos monumentos arqueológicos no Brasil. Boletim Museu Parense Emílio Goeldi, v. 4, n. 3, p. 421-435, 2009. Disponível em: http://www.scielo.br/scielo.php?script=sci_arttext\&pid=S1981$81222009000300005 \& \operatorname{lng}=e n \& n r m=$ iso. Acesso em: 28 jul 2020.

SIMMONS, John E. Things great and small: collections management policies. American Alliance of Museums, Washington, 2017.

SMANIA-MARQUES, Roberta; SILVA, Rejâne Maria Lira da. O reflexo das políticas universitárias na imagem dos museus universitários: o caso dos museus da UFBA. Museologia e Patrimônio, Rio de Janeiro, v. 4, n.1, p. 63 - 84, 2011.

UNIVERSIDADE FEDERAL DO RIO DE JANEIRO. Estatuto. Rio de Janeiro, 2019a. Disponível em: https://ufrj.br/estatuto-da-ufrj. Acesso em: 10 mar. 2020.

UNIVERSIDADE FEDERAL DO RIO DE JANEIRO. Museu Histórico Nacional. Organograma do Museu Nacional. Rio de Janeiro, 2020. Disponível em: http://www.museunacional.ufrj.br/ dir/omuseu/organograma.html. Acesso em: 27 jul. 2020.

UNIVERSIDADE FEDERAL DO RIO DE JANEIRO. Museu Histórico Nacional. Regimento do Museu Nacional. In: Separata do Boletim da UFRJ, n. 32, 12 ago. 1971. Disponível em: http:// www.museunacional.ufrj.br/obrasraras/RMN.html. Acesso em: 27 jul. 2020.

UNIVERSIDADE FEDERAL DO RIO DE JANEIRO. Portaria n. 12709, de 19 de novembro de 2019b. Boletim, Rio de Janeiro, n. 48, p. 70, 28 nov. 2019. Disponível em: http://siarq.ufrj.br/ images/bufrj/2019/48-2019.pdf. Acesso em: 10 mar. 2020.

UNIVERSIDADE FEDERAL DO RIO DE JANEIRO. Regimento geral. Rio de Janeiro, 2019c. Disponível em: https://consuni.ufrj.br/images/Legislacao/Regimento_Geral_1970_ atualizado_-_30-05-2019.pdf. Acesso em: 10 mar. 2020.

UNIVERSIDADE FEDERAL DO RIO DE JANEIRO. Resolução CEPG $n .1$, de $1^{\circ}$ de dezembro de 2006. Disponível em: http://posgraduacao.ufrj.br/public/suporte/pr2/cepg/ resolucaoCEPG/2006_01.pdf?1595418495. Acesso em: 22 jul. 2020.

\section{(cc) $\mathrm{EY}-\mathrm{Wc}-\mathrm{BA}$}

